\title{
Pulmonary Lavage in Preterm Lambs
}

\author{
THOMAS H. SHAFFER, ${ }^{19}$ JAMES D. FERGUSON, PETER A. KOEN, GORDON D. MOSKOWITZ, AND \\ MARIA DELIVORIA-PAPADOPOULOS \\ Departments of Physiology and Pediatrics, School of Medicine, University of Pennsylvania, Philadelphia, \\ Pennsylvania, USA
}

\begin{abstract}
Summary
Pulmonary function was studied before and after bilateral lung Iavage with oxygenated FC-80 fluorocarbon liquid in seven preterm lambs, 134 days of gestation. Measurements of transpulmonary pressure, air flow, tidal volume, and functional residual capacity (FRC) enabled calculations of lung resistance and compliance, specific compliance, and work of breathing. Immediately postlavage, arterial oxygen tension $\left(\mathrm{PaO}_{2}\right)$ decreased significantly $(P<$ 0.05 ) by $41 \%$ from control values. In addition, at $1 \mathrm{hr}$ postlavage, lung compliance significantly decreased $(P<0.01)$ by $43 \%$ from control levels. Lung resistance, FRC, work of breathing, arterial carbon dioxide tension, and $\mathrm{pH}$ postlavage were not significantly different from prelavage values. The mean volume of $\mathrm{FC}-80$ remaining in the lungs at $1 \mathrm{hr}$ postlavage was $32 \%$ of the instilled volume. These data indicate that lung lavage with a low surface tension liquid has a relatively small effect on lung mechanics of the premature lung.
\end{abstract}

\section{Speculation}

Adequate blood gas tensions and $\mathrm{pH}$ levels can be maintained both during and after bilateral fluorocarbon lavage with relatively small changes in lung mechanics. Based upon these findings, it is appealing to speculate that bilateral fluorocarbon lavage may be useful as a means of alveolar debridement, particularly in aspiration syndromes of the newborn.

Liquid ventilation in mammalian species has been studied by various investigators $(1,3,4,6-8,10,11)$, including the present authors $(10,11)$. Among the various liquids employed, fluorocarbons such as FC-80 were recognized as the most useful for conducting oxygen-carbon dioxide transport studies because of their capacity for dissolving large volumes of respiratory gases at atmospheric pressure. Employing forced ventilation techniques, several investigators have found that adult dogs could be supported by ventilation with fluorocarbons for prolonged periods and demonstrated survival after such ventilation.

In recent studies, preterm lambs demonstrated remarkably good pulmonary gas exchange and acid-base balance following long term (1-3 hr) liquid ventilation with FC-80. Peak intratracheal pressures measured after return to air breathing were significantly reduced as compared to preliquid ventilation values. In similar experiments with distressed preterm minipigs it was found that static lung compliance improved after $20 \mathrm{~min}$ of fluorocarbon ventilation (7). In both these studies it was speculated that the improved lung function was due to residual low surface tension fluorocarbon lining the alveoli and acting as an artificial surfactant. Based on these results it has been suggested that a brief lavage with fluorocarbon liquid may substitute for long term liquid ventilation in reducing surface-active forces in immature lungs.

The purpose of the present investigation is to determine the effects of a brief, bilateral lung lavage with low surface tension liquid on the arterial blood gases, $\mathrm{pH}$, and lung mechanics of the preterm lamb.

\section{MATERIALS AND METHODS}

PREPARATION OF LAMB

Seven lambs at a mean gestational age of 134 days (145-150 days term) and a mean birthweight of $3.8 \mathrm{~kg}$ were delivered by cesarean section and prepared for experimentation as previously described $(11,12)$. After weighing and drying the lamb, it was placed upright in an animal sling. The tracheal tube was then connected to a volume-controlled piston pump respirator (Harvard small animal respirator). Initially, tidal volume was set for $15 \mathrm{ml} / \mathrm{kg}$ at a pump frequency of $40-50$ breaths $/ \mathrm{min}$, with equal periods of inspiration and expiration at $100 \%$ inspired oxygen concentration $\left(\mathrm{F}_{1} \mathrm{O}_{2}\right)$. Care was taken to maintain thoracic pressure below $25 \mathrm{~cm} \mathrm{H} \mathrm{H}_{2} \mathrm{O}$ in order to prevent pneumothorax upon connection to the ventilator. Tidal volume and frequency of the ventilator were adjusted until arterial oxygen and carbon dioxide were in a satisfactory range $\left(\mathrm{PaO}_{2}>50 \mathrm{~mm} \mathrm{Hg}\right.$ and $\mathrm{PaCO}_{2}<60$ $\mathrm{mm} \mathrm{Hg}$ ). If $\mathrm{pH}$ fell below 7.25 after $\mathrm{PaCO}_{2}$ was stabilized below $60 \mathrm{~mm} \mathrm{Hg}$, additional bicarbonate solution was administered iv to make up for the base deficit using the formula:

$$
\mathrm{mEq} \text { base needed }=- \text { base excess }(\mathrm{mEq} / \mathrm{liter}) \times \text { body wt } \times 0.3
$$

An iv drip of $10 \%$ glucose was maintained at $5 \mathrm{ml} / \mathrm{hr} / \mathrm{kg}$.

\section{BLOOD GAS DETERMINATION}

Arterial blood gases were measured every $15 \mathrm{~min}$ on $1-\mathrm{ml}$ samples after $3 \mathrm{ml}$ had been withdrawn to clear out the carotid catheter. These $3 \mathrm{ml}$ were reinfused followed by $1.5 \mathrm{ml}$ heparinized, $0.9 \%$ saline solution. The blood samples were analyzed immediately for oxygen and carbon dioxide gas tension and $\mathrm{pH}$ using a Copenhagen Radiometer amplifier and cuvettes with membrane covered $\mathrm{O}_{2}$ and $\mathrm{CO}_{2}$ electrodes, and a capillary electrode for $\mathrm{pH}$.

\section{PULMONARY MECHANICS}

After the adjustment of tidal volume and frequency of the respirator to yield satisfactory and reproducible blood gases in the lamb, they were held constant and pulmonary function was determined. Mechanics of breathing were studied by simultaneously monitoring transpulmonary pressure, inspiratory and expiratory flow rates, and tidal volume. Transpulmonary pressure was obtained by subtracting intraesophageal pressure from tracheal pressure. Intraesophageal pressure was measured with an esophageal balloon, $2.5 \mathrm{~cm}$ in length, $0.3 \mathrm{~mm}$ in diameter, on a polyethylene 200 tube connected to one side of a Statham PM 131TC differential strain gauge transducer with a low volume adapter inserted at the inlet. After the balloon was filled with $0.5 \mathrm{ml}$ air it was positioned in approximately the lower third of the esophagus. The esophageal catheter was protected at the mouth with a polyvinyl chloride connecting tube in order to prevent the unanesthetized lamb from chewing it.

Air flow was measured with a Fleisch no. 1 pneumotachograph (dead space $15 \mathrm{ml}$ ) connected to a Statham PM 283 TC differential strain gauge pressure transducer of low volume displacement. 
Records of dynamic lung compliance and resistance were made on Electronics for Medicine DR-8 vector scope (2) and a model 5 Grass polygraph recorder. The transducer and esophageal balloon system was tested for transient response and did not introduce phase lag or damping in the frequency range encountered $(0.1-4.0$ $\mathrm{Hz}$ ). Before the dynamic compliance and resistance measurements, the tidal volume and breathing frequency were maintained at a constant rate. The pneumotachograph was placed in the ventilatory circuit only during the pulmonary mechanics measurements. Postlavage pulmonary function measurements were made at the same ventilator settings as prelavage measurements.

Functional residual capacity was measured by a rebreathing neon dilution method as previously reported $(12,13)$. Gas mixtures were analyzed for neon concentration with a Fisher gas partitioner, model $25 \mathrm{~V}$. The FRC was calculated as follows:

$$
\mathrm{FRC}=\mathrm{Vi}(\mathrm{Ci} / \mathrm{Cf})-\mathrm{Vf}
$$

where $\mathrm{Vi}$ is initial bag volume, $\mathrm{Ci}$ is initial neon concentration, $\mathrm{Cf}$ is final neon concentration, and $\mathrm{Vf}$ is final bag volume. In designing the circuit we made use of three electronically operated fast closing valves (closure time within $3 \mathrm{msec}$ ) automatically sequenced by a relay built into the Harvard respirator. Dead space of the system, including the endotracheal tube and valve, was 10.8 $\mathrm{ml}$.

The initial and final neon mixtures were analyzed on a Fisher (model $25 \mathrm{~V}$ ) gas partitioner. Equilibration time of neon during rebreathing required $50-100 \mathrm{sec}$, depending upon the tidal volume and breathing rate. The final and initial bag volumes were determined with a calibrated syringe. An accuracy of $\pm 11 \%$ was determined on known test volumes. All FRC measurements were corrected to body temperature and pressure.

Initial pulmonary function measurements were made after arterial blood gases and $\mathrm{pH}$ of the lambs were stabilized in the control period. The duration of the control period varied among the lambs (1-2 hr postnatal). Sequential pulmonary function measurements (8-12 determinations/lamb) were made at $10 \mathrm{~min}$ and $1 \mathrm{hr}$ postlavage. Statistical variation in lung mechanics measurements based on the $8-12$ determinations was less than $15 \%$ in individual lambs.

The statistical significance of all these parameters measured postlavage was arrived at using the paired Student's $t$-test.

\section{LAVAGE PROCEDURE}

After baseline pulmonary mechanics had been measured on the steady state lambs, the animal was ready for lung lavage. The lamb was removed from the respirator at end expiration and immediately connected to a suspended reservoir containing warmed $\left(39^{\circ}\right)$, oxygenated $\left(\mathrm{PO}_{2}>500 \mathrm{~mm} \mathrm{Hg}\right) \mathrm{FC}-80$ liquid (Fig. 1). A volume equivalent to the measured FRC of the lungs was slowly instilled from the reservoir via the tracheal cannula into the animal's lungs. Postural and thoracic manipulations were performed to force out any large pockets of oxygen which might have become trapped in the lungs after instillation of the liquid. Such gas was free to escape into the reservoir. Since the animal was previously hyperventilated with $100 \%$ oxygen, it was assumed that all gas remaining in the lungs was oxygen, which was either absorbed by the liquid or utilized by animal metabolism. After 2-4 min the liquid was drained from the lung via gravity into a graduated cylinder, and the volume was measured. Blood gases and pulmonary mechanics were measured subsequent to reconnection to the ventilator at $10 \mathrm{~min}$ and $1 \mathrm{hr}$ postlavage. Sequential drainings of fluorocarbon were collected during the recovery period.

\section{RESULTS}

Mean values \pm the SE of the mean (SEM) for lung compliance/weight $\left(C_{L}\right)$, specific lung compliance $\left(C_{S}\right)$, and $F R C$ normalized by weight for all lambs are presented at pre- and postlavage in Figure 2. Immediately postlavage, $\mathrm{FRC} / \mathrm{kg}$ decreased by

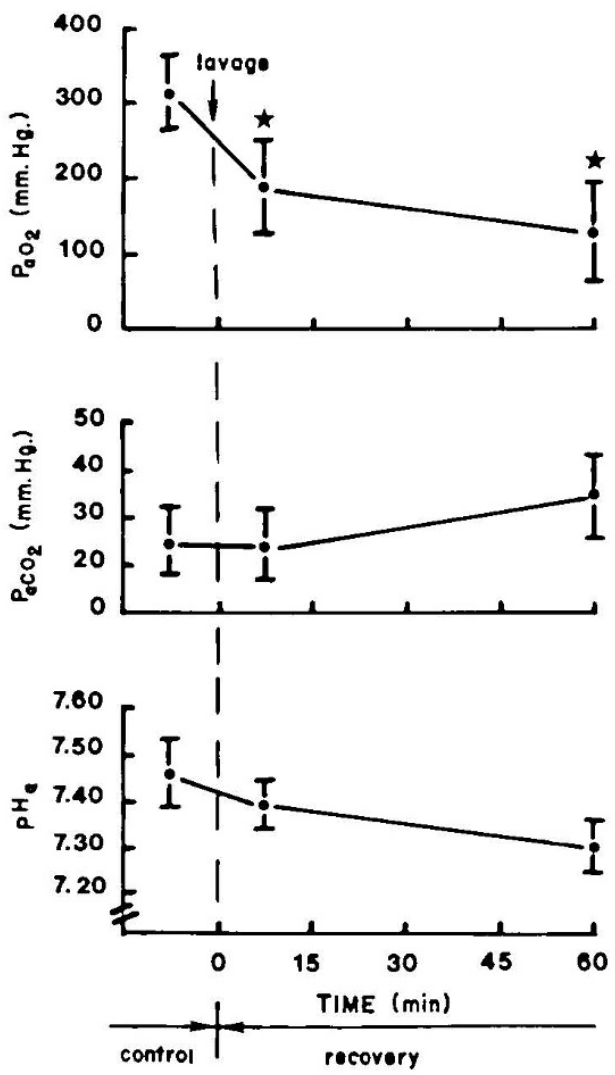

Fig. 1. Schematic of lavage procedure. A volume of FC-80 equivalent to the FRC of the lamb enters the lung. After several minutes, the liquid drains into a collecting cylinder.

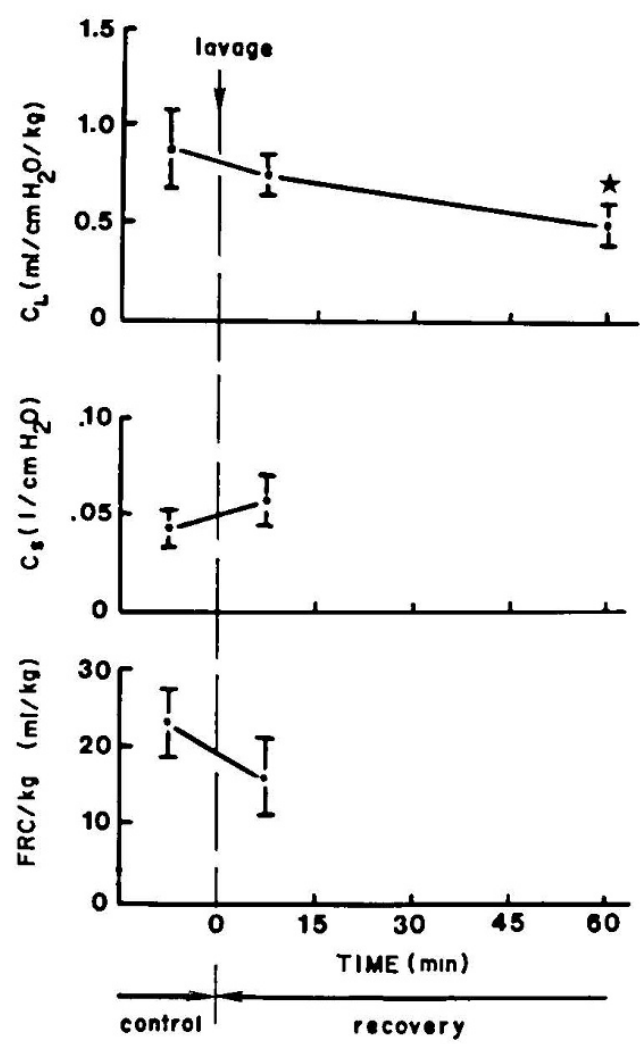

Fig. 2. Lung compliance/weight, $\mathrm{C}_{\mathrm{L}}$, specific compliance, $\mathrm{C}_{\mathrm{S}}$, and $\mathrm{FRC}$ /weight for seven premature lambs before and after bilateral FC- 80 lavage $(* P<0.05)$. 
$22 \%$. The mean decrease in FRC was statistically the same $(P>$ 0.05 ) as the mean FC- 80 volume remaining in the lung postlavage, that is, $24.5 \mathrm{ml}$ and $18.6 \mathrm{ml}$, respectively. Available data were not sufficient for reporting statistical differences in FRC at $1 \mathrm{hr}$ postlavage since FC-80 vapor frequently interfered with gas chromatography used in the measurement of FRC. Lung compliance per weight decreased by $16 \%$ immediately postlavage, and after 1 hr into the recovery period, significantly decreased $(P<0.01) 43 \%$ from control values. Specific compliance, as shown in Figure 2, increased $32 \%$ from control values within 5-10 min after lavage. Statistical comparisons at $1 \mathrm{hr}$ postlavage could not be computed for $\mathrm{C}_{\mathrm{S}}$.

Similarly, mean values \pm SEM for inspiratory resistance $\left(R_{I}\right)$, expiratory resistance $\left(\mathrm{R}_{\mathrm{E}}\right)$, and work of breathing normalized per weight $(\mathrm{W} / \mathrm{kg})$, are presented for all lambs in Figure 3 . There were no significant changes in airway resistance or work of breathing from control values during the recovery period. It is also noteworthy that expiratory airway resistance was found to be significantly greater $(P<0.05)$ than inspiratory resistance both before and after lung lavage.

In Figure 4, mean values \pm SEM for arterial oxygen tension

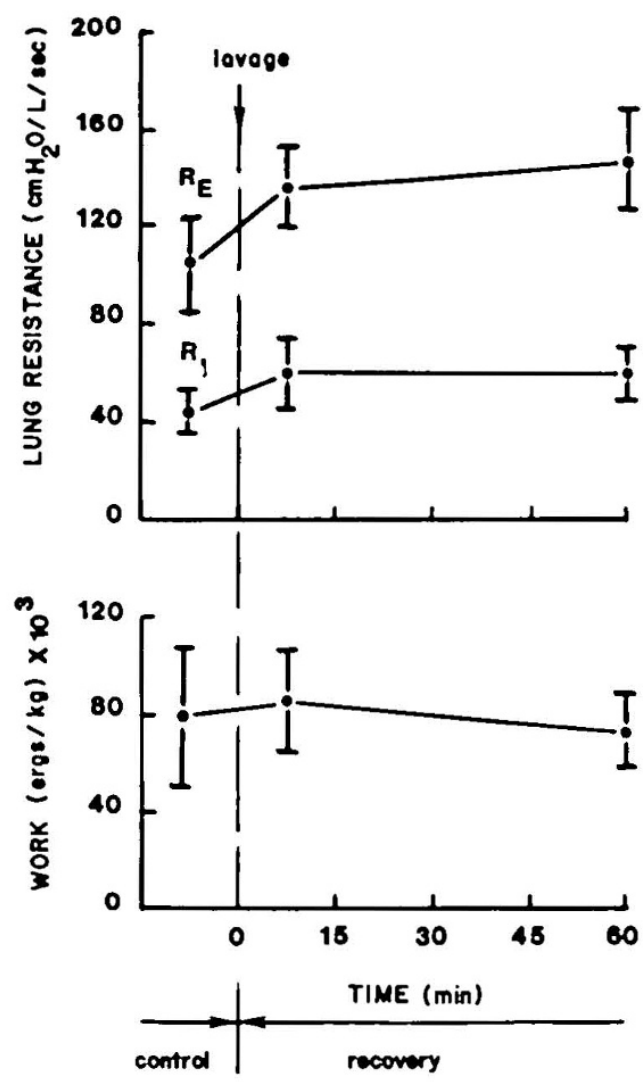

Fig. 3. Lung resistance for inspiration $\left(R_{\mathrm{I}}\right)$ and expiration $\left(\mathrm{R}_{\mathrm{E}}\right)$, and work/weight, $\mathrm{W} / \mathrm{kg}$, for seven premature lambs before and after bilateral FC-80 lung lavage.

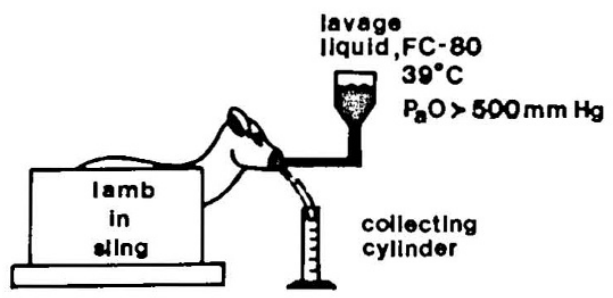

Fig. 4. Arterial oxygen tension, $\mathrm{PaO}_{2}$, arterial carbon dioxide tension, $\mathrm{PaCO}_{2}$, and $\mathrm{pH}$ for seven premature lambs before and after bilateral FC80 lung lavage. All lambs received intermittent positive pressure ventilation with an $\mathrm{F}_{1} \mathrm{O}_{2}$ of $1.0\left({ }^{*} \mathrm{P}<0.05\right)$.
$\left(\mathrm{PaO}_{2}\right)$, carbon dioxide tension $\left(\mathrm{PaCO}_{2}\right)$, and $\mathrm{pH}$ are presented for all lambs pre- and postlavage. Arterial oxygen tension decreased $41 \%$ from control level $(P<0.05)$ immediately after lavage and $57 \%$ from control level $(P<0.05) 1$ hr postlavage. $\mathrm{PaCO}_{2}$ and $\mathrm{pH}$ did not vary significantly from control values over the recovery period.

At $1.5 \mathrm{hr}$ postlavage the experiment was terminated and postmortem examination of all lambs showed poorly aerated, hemorrhagic, and friable lungs. In general the individual lobes appeared to be collapsed and failed to float when placed in water. The gross appearance of these lungs was comparable to that of lungs from lambs of similar gestational age and weight which had been ventilated with gas for several hours after cesarean section delivery, excised, and examined (12).

\section{DISCUSSION}

The premature lambs employed in this study demonstrated difficulty in breathing and required mechanical ventilation. The clinical and pathologic profile $(12,14)$, as well as the control pulmonary function (12), of these animals was consistent with previous studies done with lambs of similar gestational age.

Decreased arterial oxygen tension has frequently been reported in the literature $(5,9)$ as one of the major problems associated with lavage procedures. In the present study, however, physiologic levels of $\mathrm{PaO}_{2}, \mathrm{PaCO}_{2}$, and $\mathrm{pH}$ were maintained throughout the recovery period. Maintenance of adequate blood gas tensions after fluorocarbon lavage is related to these liquids' capacity for dissolving respiratory gases at atmospheric pressure. The slight decrease in $\mathrm{PaO}_{2}$ after lavage could be attributed to the decrease in $\mathrm{FRC}$, the reduced diffusibility of oxygen through the residual fluorocarbon layer, and the decrease in alveolar $\mathrm{PO}_{2}$ secondary to FC-80 vapor in the lung ( $57 \mathrm{~mm} \mathrm{Hg}$ at $\left.37^{\circ}\right)$.

Premature mammals typically display an instability of temperature control at birth; a relatively large heat loss from the body is due to evaporation of surface liquid and excess radiation of body heat. Since FC-80 has a high vapor pressure, and its primary mechanism for removal from the lungs is evaporation, it was initially of concern that such heat loss could compromise the lambs. In light of this, rectal temperature was monitored during the recovery period. Mean temperature decreased by only $1^{\circ}$, indicating that residual FC-80 evaporation $(68 \%$ of the instilled volume) did not stress the animals thermally.

These data indicate that lung lavage with a low surface tension liquid (15 dynes $/ \mathrm{cm})$ has a relatively small effect on lung mechanics, as opposed to the marked improvement seen following liquid ventilation (11). It does not, therefore, appear that a brief lavage with low surface tension fluorocarbon can substitute for long term liquid ventilation as a method for reducing surfaceactive forces and improving lung mechanics in premature lungs.

\section{REFERENCES AND NOTES}

1. Clark, L. C. and Gollan, F. Survival of mammals breathing organic liquid equilibriated with oxygen at atmospheric pressure. Science. 152: 1755 (1966).

2. Mead. J.. and Whittenberger. J. L.: Physical properties of human lungs measured during spontaneous respiration. J. Appl. Physiol.. 5: 779 (1953).

3. Modell, J. H.. Newby. E. J.. and Ruiz. B. C.: Longterm survival of dogs after breathing oxygenated fluorocarbon liquid. Fed. Proc.. 2y/5): 1731 (1970).

4. Modell. J. G.. Titam, M. K.. Modell, J. H.. Calderwood. H. W.. and Ruiz. B. C.: Distribution and retention of fluorocarbon liyuid in mice and dogs after injection or liquid ventilation. Toxicol. Appl. Pharmacol.. 26: 86 (1973).

5. Rogers. R. M.. Braunstein. M. S., and Shuman. J. F.: Role of bronchopulmonary lavage in the treatment of respiratory failure: A review. Chest, $62(5): 95 \mathrm{~s}$ (1972).

6. Ruefer, R.: Surfactant and alveolar surface forces after breathing of an inert fluorinated liquid. Fed. Proc., 29(5): $1813(1970)$.

7. Ruefer. R., and Spitzer. H. L.: Liquid ventilation in the respiratory distress syndrome. Chest. 6h: 29s (1974).

8. Saga. S.. Modell, J. H.. Calderwood. H. W.. Lucas. A. J.. Tham. M. K.. and Swenson. E. W.: Pulmonary function after ventilation with fluorocarbon liquid P-12F (Caroxin-F). J. Appl. Physiol.. 3f(2): 160 (1970).

9. Seard. C.. et al: Simultaneous bilateral lung lavage (alveolar washing) using partial pulmonary bypass. Ann. Rev. Circ. Dis.. 101: 877 (1970).

10. Shaffer, T. H., and Moskowitz. G. D.: Demand-controlled liquid ventilation of the lungs. J. Appl. Physiol.. 3612): 208 (1974). 
11. Shaffer. T. H.. Rubenstein. S. D.. Moskowitz. G. D.. and Delivoria-Papadopoulos. M.: Gaseous exchange and acid-base balance in preterm lambs during hquid ventilation since birth. Pediat. Res. 11): 227 (1976).

12. Shaffer. T. H.. Delivoria-Papadopoulos. M.. Arcinue. E.. Paez. P. D.. and DuBois, A. B.: Variation of pulmonary mechanics and acid-base balance in premature lambs during the first six hours of life. Resp. Physiol.. 28: 179 (1976).

13. Shaffer. T H Koen. P. A and Delivoria-Papadopoulos M.: Instrumentation for measuring functional residual capacity in newborn infants and small animals. Pediat. Res.. 11: 578 (1977).

14. Stahlman. M.. LeQuire. V. S.. Young. W. C.. Merrill. R. E.. Birmingham. R. T. Pavne, G. A.. and Gray, J.: Pathophysiology of respiratory distress in newborn lambs. Amer. J. Dis. Child.. 108: 375 (1964).

15. Tuazon. J. G.. Modell. J. H.. Hood. C. I.. and Swenson. E. W.: Pulmonary function after ventilation with fluorocarbon liquid (Caroxin-D). Anesthesiol- ogy. $38(2): 134$ (1973)

16. Coauthors James D. Ferguson. Peter A. Koen, and Gordon D. Moskowitz are members of the Department of Biomedical Engineering and Science of Drexe University, Philadelphia. Pennsylvania.

17. Results from this manuscript were presented in part at the Annual Meeting of the Society for Pediatric Research. April 1977, in San Francisco. California

18. This research was supported in part by USPHS Grants HL-17154. HL-19402. and Program Project Grant HL-08805. all from the NHLI.

19. Requests for reprints should be addressed to: Dr. Thomas H. Shaffer, Department of Physiology, A201 Richards Building. G/4, School of Medicine, University of Pennsylvania, Philadelphia, PA 19104.

20. Received for publication May 24, 1977.

21. Accepted for publication August 16, 1977 . 